\title{
Magnetohydrodynamic Mixed Convection Stagnation-Point Flow of a Power-Law Non-Newtonian Nanofluid towards a Stretching Surface with Radiation and Heat Source/Sink
}

\author{
Macha Madhu and Naikoti Kishan \\ Department of Mathematics, Osmania University, Hyderabad, Telangana 500007, India \\ Correspondence should be addressed to Macha Madhu; madhumaccha@gmail.com
}

Received 29 September 2014; Revised 28 January 2015; Accepted 29 January 2015

Academic Editor: Robert Spall

Copyright (C) 2015 M. Madhu and N. Kishan. This is an open access article distributed under the Creative Commons Attribution License, which permits unrestricted use, distribution, and reproduction in any medium, provided the original work is properly cited.

\begin{abstract}
Two-dimensional MHD mixed convection boundary layer flow of heat and mass transfer stagnation-point flow of a non-Newtonian power-law nanofluid towards a stretching surface in the presence of thermal radiation and heat source/sink is investigated numerically. The non-Newtonian nanofluid model incorporates the effects of Brownian motion and thermophoresis. The basic transport equations are made dimensionless first and the complete nonlinear differential equations with associated boundary conditions are solved numerically by finite element method (FEM). The numerical calculations for velocity, temperature, and nanoparticles volume fraction profiles for different values of the physical parameters to display the interesting aspects of the solutions are presented graphically and discussed. The skin friction coefficient, the local Nusslet number and the Sherwood number are exhibited and examined. Our results are compatible with the existing results for a special case.
\end{abstract}

\section{Introduction}

Many of the non-Newtonian fluids encountered in chemical engineering processes are known to follow the empirical Ostwald-de Waele power-law model. The concept of boundary layer was applied to power-law fluids by Schowalter [1]. Acrivos [2] investigated the boundary layer flows for such fluids in 1960; since then, a large number of related studies have been conducted because of their importance and presence of such fluids in chemicals, polymers, molten plastics, and others. The theory of non-Newtonian fluids offers mathematicians, engineers, and numerical specialists varied challenges in developing analytical and numerical solutions for the highly nonlinear governing equations. However, due to the practical significance of these non-Newtonian fluids, many authors have presented various non-Newtonian fluid models like Elbashbeshy et al. [3], Nadeem et al. [4], Nadeem et al. [5], Nadeem et al. [6], Nadeem and Akbar [7], Nadeem and Ali [8], Buongiorno [9], and Łukaszewicz [10]. Many interesting applications of non-Newtonian power-law fluids were presented by Shenoy [11]. Details of the behavior of
non-Newtonian fluids for both steady and unsteady flow situations, along with mathematical models, are studied by Astarita and Marrucci [12], Bohme [13], and Kishan and Shashidar Reddy [14].

Nanotechnology has immense applications in industry since materials with sizes of nanometers exhibit unique physical and chemical properties. Fluids with nano-scaled particles interaction are called nanofluid. It represents the most relevant technological cutting edge currently being explored. Nanofluid heat transfer is an innovative technology which can be used to enhance heat transfer. Nanofluid is a suspension of solid nanoparticles $(1-100 \mathrm{~nm}$ diameters) in conventional liquids like water, oil, and ethylene glycol. Depending on shape, size, and thermal properties of the solid nanoparticles, the thermal conductivity can be increased by about $40 \%$ with low concentration ( $1 \%-5 \%$ by volume) of solid nanoparticles in the mixture. The nanoparticles used in nanofluid are normally composed of metals, oxides, carbides, or carbon nanotubes. Water, ethylene glycol, and oil are common examples of base fluids. Nanofluids have their major applications in heat transfer, including microelectronics, fuel 
cells, pharmaceutical processes, and hybrid-powered engines, domestic refrigerator, chiller, nuclear reactor coolant, grinding, space technology, and boiler flue gas temperature reduction. They demonstrate enhanced thermal conductivity and convective heat transfer coefficient counterbalanced to the base fluid. Nanofluids have been the core of attention of many researchers for new production of heat transfer fluids in heat exchangers, plants, and automotive cooling significations, due to their enormous thermal characteristics, Nadeem et al. [15]. The nanofluid is stable; it introduces very little pressure drop, and it can pass through nanochannels (e.g., see Zhou [16]). The word nanofluid was coined by Choi [17]. Xuan and $\mathrm{Li}$ [18] pointed out that, at higher nanoparticle volume fractions, the viscosity increases sharply, which suppresses heat transfer enhancement in the nanofluid. Therefore, it is important to carefully select the proper nanoparticle volume fraction to achieve heat transfer enhancement. Buongiorno noted that the nanoparticles' absolute velocity can be viewed as the sum of the base fluid velocity and a relative velocity (which he called the slip velocity). He considered in turn seven slip mechanisms: inertia, Brownian diffusion, thermophoresis, diffusiophoresis, Magnus effect, fluid drainage, and gravity settling.

Forced convective heat transfer can be enhanced effectively by using nanofluids, a type of fluid adding different suspending nanoparticles into the conventional base liquid (Pak and Cho [19], Wen and Ding [20], and Ding et al. [21]). However, the characteristics of nanofluids and the mechanism of the enhancement of the forced convective heat transfer of nanofluids are still not clear. Recently, nanofluids have attracted much attention since anomalously large enhancements in effective thermal conductivities were reported over a decade ago (Masuda et al. [22] and Keblinski et al. [23]). Subsequent studies by various groups have reported that nanofluids also have other desirable properties and behaviours such as enhanced wetting and spreading (Wasan and Nikolov [24] and Chengara et al. [25]), as well as increased critical heat fluxes under boiling condition (You et al. [26]).

Boundary layer flow and heat transfer over a continuously stretched surface have received considerable attention in recent years. This is because of the various possible engineering and metallurgical applications such as hot rolling, metal and plastic extrusion, wire drawing, glass fibre production, continuous casting, crystal growing, and paper production. Crane [27] was the first to investigate the boundary layer flow caused by a stretching sheet moving with linearly varying velocity from a fixed point whilst the heat transfer aspect of the problem was investigated by Carragher and Crane [28] under the conditions that the temperature difference between the surface and the ambient fluid was proportional to the power of the distance from a fixed point. The behaviour of non-Newtonian nanofluids could be useful in evaluating the possibility of heat transfer enhancement in various processes of these industries. Several investigators have studied non-Newtonian nanofluid transport in various geometries under various boundary conditions in porous or nonporous media. Ellahi et al. [29] have elaborated that non-Newtonian nanofluids have potential roles in physiological transport as biological solutions and also in polymer melts, paints, and so forth.

The effect of heat source/sink is very important in cooling process industries. Effects of heat source/sink on the boundary layer flow over a stretching sheet were studied by Cortell [30], Abel et al. [31], Dessie and Kishan [32], Tufail et al. [33], Elbashbeshy and Bazid [34], and Chen [35]. In fact, heat source/sink concepts in fluids have relevance in problems dealing with chemical reactions geonuclear repositions and these concerned with dissociating fluids. Transport phenomena associated with magnetohydrodynamics arise in physics, geophysics, astrophysics, and many branches of chemical engineering which include crystal magnetic damping control, hydromagnetic chromatography, conducting flow in trickle-bed reactors, and enhanced magnetic filtration control (Prasad et al. [36]).

In the present paper, our aim is to investigate the effects of MHD, heat source/sink, and thermal radiation on heat and mass transfer by mixed convection boundary layer stagnation point flow of non-Newtonian power-law fluid towards a stretching surface with a nanofluid. The effects of Brownian motion and thermophoresis are included for the nanofluid. Numerical solutions of the boundary layer equations are obtained and a discussion is provided for several values of the nanofluid parameters governing the problem. The dimensionless profiles of velocity, temperature, and nanoparticle volume fraction as well as the skin friction coefficient, local Nusselt number, and Sherwood number for the different flow parameters have been discussed.

\section{Mathematical Formulation}

Consider steady, laminar, heat, and mass transfer by mixed convection, boundary layer stagnation-point flow of an electrically conducting, optically dense, and non-Newtonian power-law fluid obeying the Ostwald-de Waele model (see [37]) past a heated or cooled stretching vertical surface in the presence of thermal radiation. It is assumed that the stretching velocity is given by $u_{w}(x)=c x$, and the velocity distribution in frictionless potential flow in the neighborhood of the stagnation point at $x=y=0$ is given by $U(x)=a x$. We assumed that the uniform wall temperature $T_{w}$ and nanoparticles volume fraction $C_{w}$ are higher than those of their full stream values $T_{\infty}, C_{\infty}$. A uniform magnetic field is applied in the $y$-direction normal to the flow direction. The magnetic Reynolds number is assumed to be small so that the induced magnetic field is neglected. In addition, the Hall effect and the electric field are assumed to be negligible. The small magnetic Reynolds number assumption uncouples the Navier-Stokes equations from Maxwell's equations. All physical properties are assumed to be constant except for the density in the buoyancy force term. By invoking all of the boundary layer, Boussinesq and Rosseland diffusion approximations, the governing equations for this investigation can be written as

$$
\frac{\partial u}{\partial x}+\frac{\partial v}{\partial y}=0,
$$




$$
\begin{gathered}
u \frac{\partial u}{\partial x}+v \frac{\partial u}{\partial y}=U \frac{d U}{d x}+\frac{1}{\rho} \frac{\partial \tau_{x y}}{\partial y}+g \beta\left(T-T_{\infty}\right) \\
+g \beta^{*}\left(C-C_{\infty}\right)-\frac{\sigma B_{0}^{2}}{\rho}(u-U), \\
u \frac{\partial T}{\partial x}+v \frac{\partial T}{\partial y}=\alpha_{m} \frac{\partial^{2} T}{\partial y^{2}}+\tau\left[D_{B} \frac{\partial C}{\partial y} \frac{\partial T}{\partial y}+\frac{D_{T}}{T_{\infty}}\left(\frac{\partial T}{\partial y}\right)^{2}\right] \\
+\frac{Q_{0}}{(\rho C)_{f}}\left(T-T_{\infty}\right)-\frac{1}{\rho C_{p}} \frac{\partial q_{r}}{\partial y}, \\
u \frac{\partial C}{\partial x}+v \frac{\partial C}{\partial y}=D_{B} \frac{\partial^{2} C}{\partial y^{2}}+\frac{D_{T}}{T_{\infty}} \frac{\partial^{2} T}{\partial y^{2}} .
\end{gathered}
$$

The associated boundary conditions are

$$
\begin{array}{r}
u=u_{w}(x)=c x, \quad v=0, \quad T=T_{w}, \quad C=C_{w} \\
\text { at } y=0, \\
u=U(x)=a x, \quad v=-a y, \quad T=T_{\infty}, \quad C=C_{\infty} \\
\text { at } y \longrightarrow \infty .
\end{array}
$$

$u, v, T$, and $C$ are the $x$ and $y$ components of velocity, temperature, and nanoparticle volume fraction, respectively. $g, \rho, \alpha_{m}, D_{B}, D_{T}, B_{0}, \beta$, and $\beta^{*}$ are the gravitational acceleration, fluid density, thermal diffusivity, Brownian diffusion coefficient, thermophoretic diffusion coefficient, magnetic field, coefficient of thermal expansion, and coefficient of concentration of expansion, respectively. The term $Q_{0}(T-$ $T_{\infty}$ ) is assumed to be the amount of heat generated or absorbed per unit volume $Q_{0}$ as a coefficient constant, which may take on either positive or negative value. When the wall temperature $T$ exceeds the free stream temperature $T_{\infty}$, the source term $Q_{0}>0$ and heat sink when $Q_{0}<0$. We have $\partial u / \partial y>0$ when $a / c>1$ (the ratio of free stream velocity and stretching velocity) which gives the shear stress as

$$
\tau_{x y}=K \frac{\partial}{\partial y}\left(\frac{\partial u}{\partial y}\right)^{n}
$$

where $K$ is the consistency coefficient and $n$ is the power-law fluid. It needs to be mentioned that, for the non-Newtonian power-law model, the case of $n<1$ is associated with shearthinning fluids (pseudoplastic fluids); $n=1$ corresponds to Newtonian fluids and $n>1$ applies to the case of shear thickening (dilatant).

Using the Rosseland approximation for radiation, the radiative heat flux is simplified as

$$
q_{r}=-\frac{4 \sigma_{1}}{3 \chi} \frac{\partial T^{4}}{\partial y}
$$

where $\sigma_{1}$ and $\chi$ are the Stefan-Boltzmann constant and the mean absorption coefficient, respectively. We assume that the temperature differences within the flow, such as the term $T^{4}$, may be expressed as a linear function of temperature.
Hence, expanding $T^{4}$ in a Taylor series about a free stream temperature $T_{\infty}$ and neglecting higher-order terms, we get

$$
T^{4}=4 T_{\infty}^{4} T-3 T_{\infty}^{4} .
$$

Using (7) and (8) in the last term of (3), we obtain

$$
\frac{\partial q_{r}}{\partial y}=-\frac{16 \sigma_{1} T_{\infty}^{3}}{3 \chi} \frac{\partial^{2} T}{\partial y^{2}}
$$

In order to reduce the governing equations into a system of ordinary differential equations, the following dimensionless parameters are introduced

$$
\begin{gathered}
\psi=\left(\frac{K / \rho}{c^{1-2 n}}\right)^{1 /(n+1)} x^{2 n /(n+1)} f(\eta), \quad \theta=\frac{T-T_{\infty}}{T_{w}-T_{\infty}}, \\
\phi=\frac{C-C_{\infty}}{C_{w}-C_{\infty}}, \quad \eta=y\left(\frac{c^{2-n}}{K / \rho}\right)^{1 /(n+1)} x^{(1-n) /(1+n)} .
\end{gathered}
$$

It is worth mentioning that the continuity equation (4) is identically satisfied from our choice of the stream function with $u=\partial \psi / \partial y$ and $v=-\partial \psi / \partial x$. Substituting the dimensionless parameters into (2)-(4) gives

$$
\begin{gathered}
n\left(f^{\prime \prime}\right)^{(n-1)} f^{\prime \prime \prime}+\left(\frac{2 n}{n+1}\right) f f^{\prime \prime}-f^{\prime 2}-M f^{\prime} \\
+M \frac{a}{c}+\frac{a^{2}}{c^{2}}+\Lambda(\theta+N \phi)=0, \\
\frac{1}{\operatorname{Pr}}\left(1+\frac{4 R_{d}}{3}\right) \theta^{\prime \prime}+\left(\frac{2 n}{n+1}\right) f \theta^{\prime}+N b \theta^{\prime} \phi^{\prime} \\
+N t \theta^{\prime 2}+Q \theta=0, \\
\phi^{\prime \prime}+\left(\frac{2 n}{n+1}\right) \operatorname{Le} f \phi^{\prime}+\frac{N t}{N b} \theta^{\prime \prime}=0 .
\end{gathered}
$$

The transformed boundary conditions are

$$
\begin{gathered}
f(0)=0, \quad f^{\prime}(0)=1, \quad \theta(0)=1, \quad \phi(0)=1, \\
f^{\prime}(\infty) \longrightarrow \frac{a}{c}, \quad \theta(\infty) \longrightarrow 0, \quad \phi(\infty) \longrightarrow 0 .
\end{gathered}
$$

The nine parameters appearing in (11) are defined as follows:

$$
\begin{gathered}
M=\frac{\sigma B_{0}^{2}}{\rho c}, \quad \Lambda=\frac{g \beta\left(T_{w}-T_{\infty}\right) x^{3} / v^{2}}{u_{w}^{2} x^{2} / v^{2}}, \\
N=\frac{g \beta^{*}\left(C_{w}-C_{\infty}\right)}{g \beta\left(T_{w}-T_{\infty}\right)}, \\
\operatorname{Pr}=\frac{v}{\alpha_{m}}\left(c^{2} \operatorname{Re}_{x}\right)^{(n-1) /(n+1)}, \quad R_{d}=\frac{4 \sigma_{1} T_{\infty}^{3}}{k \chi}, \\
N b=\frac{\tau D_{B}\left(C_{w}-C_{\infty}\right)}{v}\left(c^{2} \operatorname{Re}_{x}\right)^{(1-n) /(1+n)}, \\
N t=\frac{\tau D_{T}\left(T_{w}-T_{\infty}\right)}{T_{\infty} v}\left(c^{2} \operatorname{Re}_{x}\right)^{(1-n) /(1+n)}, \\
\mathrm{Le}=\frac{v}{D_{B}}\left(c^{2} \operatorname{Re}_{x}\right)^{(n-1) /(n+1)}, \quad Q=\frac{Q_{0}}{(\rho C)_{f}},
\end{gathered}
$$


where $\operatorname{Re}_{x}=u_{w} x / v$ is the local Reynolds number based on the stretching velocity $u_{w}(x)$ and $k$ is the thermal conductivity. It should be noted that $\Lambda>0$ corresponds to an assisting flow (heated plate), $\Lambda<0$ corresponds to an opposing flow (cooled plate), and $\Lambda=0$ yields forced convection flow.

The skin friction coefficient $C_{f_{x}}$ at the wall is given by

$$
C_{f_{x}}=2\left[f^{\prime \prime}(0)\right]^{n}\left(\frac{(c x)^{2-n} x^{n}}{K / \rho}\right)^{-1 /(1+n)},
$$

the local Nusselt number $\mathrm{Nu}_{x}$ is given by

$$
\mathrm{Nu}_{x}=-K\left(\frac{u_{w}^{2-n}}{K / \rho}\right)^{1 / n+1}\left(1+\frac{4 R_{d}}{3}\right) \theta^{\prime}(0),
$$

and the local Sherwood number $\mathrm{Sh}_{x}$ is given by

$$
\mathrm{Sh}_{x}=-D\left(\frac{u_{w}^{2-n}}{K / \rho}\right)^{1 / n+1} \phi^{\prime}(0) \text {. }
$$

\section{Method of Solution}

3.1. Finite Element Method. The finite element method is a powerful technique for solving ordinary or partial differential equations. The basic concept of FEM is that the whole domain is divided into smaller elements of finite dimensions called finite elements. This method is the most versatile numerical technique in engineering analysis and has been employed to study diverse problems in heat transfer, fluid mechanics, rigid body dynamics, solid mechanics, chemical processing, electrical systems, acoustics, and many other fields. The steps involved in the finite element analysis are as follows:

(i) discretization of the domain into elements,

(ii) derivation of element equations,

(iii) assembly of element equations,

(iv) imposition of boundary conditions,

(v) solution of assembled equations.

To solve the system of simultaneous nonlinear differential equations (11), with the boundary conditions (12a) and (12b), we assume that

$$
f^{\prime}=h
$$

the system of (11) then reduced to

$$
\begin{gathered}
n\left(h^{\prime}\right)^{(n-1)} h^{\prime \prime}+\left(\frac{2 n}{n+1}\right) f h^{\prime}-h^{2}-M h \\
+M \frac{a}{c}+\frac{a^{2}}{c^{2}}+\Lambda(\theta+N \phi)=0, \\
\frac{1}{\operatorname{Pr}}\left(1+\frac{4 R_{d}}{3}\right) \theta^{\prime \prime}+\left(\frac{2 n}{n+1}\right) f \theta^{\prime}+N b \theta^{\prime} \phi^{\prime} \\
+N t \theta^{\prime 2}+Q \theta=0, \\
\phi^{\prime \prime}+\left(\frac{2 n}{n+1}\right) \operatorname{Le} f \phi^{\prime}+\frac{N t}{N b} \theta^{\prime \prime}=0
\end{gathered}
$$

and the corresponding boundary conditions now become

$$
\begin{aligned}
& f(0)=0, \quad h(0)=1, \quad \theta(0)=1, \quad \phi(0)=1, \\
& h(\infty) \longrightarrow \frac{a}{c}, \quad \theta(\infty) \longrightarrow 0, \quad \phi(\infty) \longrightarrow 0 .
\end{aligned}
$$

For computational purposes, the $\infty$ has been shifted to $\eta=8$, without any loss of generality. The domain is divided into a set of 100 line elements, each element having two nodes.

3.2. Variational Formulation. The variational form associated with (17)-(18) over a typical linear element $\left(\eta_{e}, \eta_{e+1}\right)$ is given by

$$
\begin{gathered}
\int_{\eta_{e}}^{\eta_{e+1}} w_{1}\left\{f^{\prime}-h\right\} \mathrm{d} \eta=0, \\
\int_{\eta_{e}}^{\eta_{e+1}} w_{2}\left\{n\left(h^{\prime}\right)^{(n-1)} h^{\prime \prime}+\left(\frac{2 n}{n+1}\right) f h^{\prime}-h^{2}-M h\right. \\
\left.+M \frac{a}{c}+\frac{a^{2}}{c^{2}}+\Lambda(\theta+N \phi)\right\} \mathrm{d} \eta=0, \\
\int_{\eta_{e}}^{\eta_{e+1}} w_{3}\left\{\frac{1}{\operatorname{Pr}}\left(1+\frac{4 R_{d}}{3}\right) \theta^{\prime \prime}+\left(\frac{2 n}{n+1}\right) f \theta^{\prime}+N b \theta^{\prime} \phi^{\prime}\right. \\
\left.+N t \theta^{\prime 2}+Q \theta\right\} \mathrm{d} \eta=0, \\
\int_{\eta_{e}}^{\eta_{e+1}} w_{4}\left\{\phi^{\prime \prime}+\left(\frac{2 n}{n+1}\right) \operatorname{Le} f \phi^{\prime}+\frac{N t}{N b} \theta^{\prime \prime}\right\} \mathrm{d} \eta=0,
\end{gathered}
$$

where $w_{1}, w_{2}, w_{3}$, and $w_{4}$ are weight functions and may be viewed as the variation in $f, h, \theta$, and $\phi$, respectively.

3.3. Finite Element Formulation. The finite element model from (20) by substituting finite element approximations of the form

$$
\begin{aligned}
f=\sum_{j=1}^{2} f_{j} \psi_{j}, \quad h=\sum_{j=1}^{2} h_{j} \psi_{j}, \quad \theta=\sum_{j=1}^{2} \theta_{j} \psi_{j}, \\
\phi=\sum_{j=1}^{2} \phi_{j} \psi_{j}
\end{aligned}
$$

with $w_{1}=w_{2}=w_{3}=w_{4}=\psi_{i},(i=1,2)$, where $\psi_{i}$ are the shape functions for a two-noded linear element $\left(\eta_{e}, \eta_{e+1}\right)$ and are taken as

$$
\psi_{1}^{(e)}=\frac{\eta_{e+1}-\eta}{\eta_{e+1}-\eta_{e}}, \quad \psi_{2}^{(e)}=\frac{\eta-\eta_{e}}{\eta_{e+1}-\eta_{e}}, \quad \eta_{e} \leq \eta \leq \eta_{e+1} .
$$

The finite element model of the equations thus formed is given by

$$
\left[\begin{array}{llll}
{\left[K^{11}\right]} & {\left[K^{12}\right]} & {\left[K^{13}\right]} & {\left[K^{14}\right]} \\
{\left[K^{21}\right]} & {\left[K^{22}\right]} & {\left[K^{23}\right]} & {\left[K^{24}\right]} \\
{\left[K^{31}\right]} & {\left[K^{32}\right]} & {\left[K^{33}\right]} & {\left[K^{34}\right]} \\
{\left[K^{41}\right]} & {\left[K^{42}\right]} & {\left[K^{43}\right]} & {\left[K^{44}\right]}
\end{array}\right]\left[\begin{array}{l}
\{f\} \\
\{h\} \\
\{\theta\} \\
\{\phi\}
\end{array}\right]=\left[\begin{array}{l}
\left\{b^{1}\right\} \\
\left\{b^{2}\right\} \\
\left\{b^{3}\right\} \\
\left\{b^{4}\right\}
\end{array}\right],
$$


where $\left[K^{m n}\right]$ and $\left[b^{m}\right](m=1,2)$ are defined as

$$
\begin{aligned}
& K_{i j}^{11}=\int_{\eta_{e}}^{\eta_{e+1}} \psi_{i} \frac{\mathrm{d} \psi_{j}}{\mathrm{~d} \eta} \mathrm{d} \eta, \quad K_{i j}^{12}=-\int_{\eta_{e}}^{\eta_{e+1}} \psi_{i} \psi_{j} \mathrm{~d} \eta, \\
& K_{i j}^{13}=K_{i j}^{14}=K_{i j}^{21}=0, \\
& K_{i j}^{22}=\int_{\eta_{e}}^{\eta_{e+1}}\left[-n\left(\overline{h^{\prime}}\right)^{n-1} \frac{\mathrm{d} \psi_{i}}{\mathrm{~d} \eta} \frac{\mathrm{d} \psi_{j}}{\mathrm{~d} \eta}\right. \\
& \left.+\left(\frac{2 n}{n+1}\right) \bar{f} \psi_{i} \frac{\mathrm{d} \psi_{j}}{\mathrm{~d} \eta}-\bar{h} \psi_{i} \psi_{j}-M \psi_{i} \psi_{j}\right] \mathrm{d} \eta, \\
& K_{i j}^{23}=\Lambda \int_{\eta_{e}}^{\eta_{e+1}} \psi_{i} \psi_{j} \mathrm{~d} \eta, \quad K_{i j}^{24}=N \Lambda \int_{\eta_{e}}^{\eta_{e+1}} \psi_{i} \psi_{j} \mathrm{~d} \eta, \\
& K_{i j}^{31}=K_{i j}^{32}=0, \\
& K_{i j}^{33}=\int_{\eta_{e}}^{\eta_{e+1}}\left[-\frac{1}{\operatorname{Pr}}\left(1+\frac{4 R_{d}}{3}\right) \frac{\mathrm{d} \psi_{i}}{\mathrm{~d} \eta} \frac{\mathrm{d} \psi_{j}}{\mathrm{~d} \eta}\right. \\
& +\left(\frac{2 n}{n+1}\right) \bar{f} \psi_{i} \frac{\mathrm{d} \psi_{j}}{\mathrm{~d} \eta}+N b \overline{\phi^{\prime}} \psi_{i} \frac{\mathrm{d} \psi_{j}}{\mathrm{~d} \eta} \\
& \left.+N t \overline{\theta^{\prime}} \psi_{i} \frac{\mathrm{d} \psi_{j}}{\mathrm{~d} \eta}+Q \psi_{i} \psi_{j}\right] \mathrm{d} \eta \\
& K_{i j}^{34}=K_{i j}^{41}=K_{i j}^{42}=0 \text {, } \\
& K_{i j}^{43}=-\frac{N t}{N b} \int_{\eta_{e}}^{\eta_{e+1}} \frac{\mathrm{d} \psi_{i}}{\mathrm{~d} \eta} \frac{\mathrm{d} \psi_{j}}{\mathrm{~d} \eta} \mathrm{d} \eta, \\
& K_{i j}^{44}=\int_{\eta_{e}}^{\eta_{e+1}}\left[-\frac{\mathrm{d} \psi_{i}}{\mathrm{~d} \eta} \frac{\mathrm{d} \psi_{j}}{\mathrm{~d} \eta}+\operatorname{Le}\left(\frac{2 n}{n+1}\right) \bar{f} \psi_{i} \frac{\mathrm{d} \psi_{j}}{\mathrm{~d} \eta}\right] \mathrm{d} \eta, \\
& b_{i}^{1}=0, \\
& b_{i}^{2}=-\left[\left(\frac{a}{c}\right)^{2}+M\left(\frac{a}{c}\right)\right] \\
& \cdot \int_{\eta_{e}}^{\eta_{e+1}} \psi_{i} \mathrm{~d} \eta-n\left(\overline{h^{\prime}}\right)^{n-1}\left(\psi_{i} \frac{\mathrm{d} h}{\mathrm{~d} \eta}\right)_{\eta_{e}}^{\eta_{e+1}} \\
& b_{i}^{3}=-\frac{1}{\operatorname{Pr}}\left(1+\frac{4 R_{d}}{3}\right)\left(\psi_{i} \frac{\mathrm{d} \theta}{\mathrm{d} \eta}\right)_{\eta_{e}}^{\eta_{e+1}}, \\
& b_{i}^{4}=-\left(\psi_{i} \frac{\mathrm{d} \phi}{\mathrm{d} \eta}\right)_{\eta_{e}}^{\eta_{e+1}}-\frac{N t}{N b}\left(\psi_{i} \frac{\mathrm{d} \theta}{\mathrm{d} \eta}\right)_{\eta_{e}}^{\eta_{e+1}}
\end{aligned}
$$

where

$$
\begin{gathered}
\bar{f}=\sum_{i=1}^{2} \overline{f_{i}} \psi_{i}, \quad \bar{h}=\sum_{i=1}^{2} \overline{h_{i}} \psi_{i}, \quad \overline{h^{\prime}}=\sum_{i=1}^{2} \overline{h_{i}^{\prime}} \psi_{i}, \\
\overline{\theta^{\prime}}=\sum_{i=1}^{2} \overline{\theta_{i}^{\prime}} \psi_{i}, \quad \bar{\phi}=\sum_{i=1}^{2} \overline{\phi_{i}^{\prime}} \psi_{i} .
\end{gathered}
$$

Each element matrix is of the order $8 \times 8$. The whole domain is divided into 100 linear elements of equal size; after
TABLE 1: Comparison of $f^{\prime \prime}(0)$ for various values of $M$ at $n=1$, between analytical solutions obtained by homotopy analysis method and finite element method in the present work in the absence of heat and mass transfer.

\begin{tabular}{lcc}
\hline$M$ & $\begin{array}{c}\text { Mahapatra et al. [38] } \\
\text { Analytical results }\end{array}$ & Present results \\
\hline 0.0 & 2.0175 & 2.01753 \\
0.5 & 2.1363 & 2.136374 \\
1.0 & 2.2491 & 2.249134 \\
1.5 & 2.3567 & 2.356684 \\
2.0 & 2.4597 & 2.459658 \\
3.0 & 2.6540 & 2.65378 \\
5.0 & 3.0058 & 3.00392 \\
\hline
\end{tabular}

assembly of all the elements equations, we obtain a matrix of the order $404 \times 404$. This system of equations as obtained after assembly of the element equations is nonlinear. Therefore, an iterative scheme must be utilized in the solution. After imposing the boundary conditions only a system of 397 equations remains for the solution, which is solved by the Gauss elimination method maintaining an accuracy of 0.0005 .

\section{Result and Discussion}

The numerical solutions of governing equations (11) with boundary conditions (12a) and (12b) have been solved by using the variational finite element method. To validate our results, the numerical computations of these skin friction coefficients, Nusselt number, and Sherwood number which are, respectively, proportional to $f^{\prime \prime}(0),-\left(1+4 R_{d} / 3\right) \theta^{\prime}(0)$, and $-\phi^{\prime}(0)$ are presented in tabular form and one result is compared with Mahapatra et al. [38]. The validation of present results has been verified with the classical case of Newtonian fluid $(n=1)$ and there is a good agreement between present and Mahapatra et al. (Table 1) [38].

To analyse the results, numerical computations have been carried out for the dimensionless velocity, temperature, and nanoparticle volume fraction distributions for the flow under considerations and are obtained and their behaviour has been discussed for various governing parameters such as magnetic parameter $M$, dimensionless mixed convection parameter $\Lambda$, concentration to thermal buoyancy ratio $N$, Prandtl number $\operatorname{Pr}$, radiation parameter $R_{d}$, heat source/sink parameter $Q$, Brownian motion $\mathrm{Nb}$, thermophoresis parameter $\mathrm{Nt}$, and Lewis number Le. Tables 2-5 show the effect of magnetic parameter $M$, power-law index $n$, dimensionless mixed convection parameter $\Lambda$, Prandtl number $\operatorname{Pr}$, radiation parameter $R_{d}$, Brownian motion $N b$, thermophoresis parameter $N t$, and Lewis number Le on the coefficient of skin friction coefficient $f^{\prime \prime}(0)$, Nusselt number $-\left(1+4 R_{d} / 3\right) \theta^{\prime}(0)$, and Sherwood number $-\phi^{\prime}(0)$, respectively. It can be seen that the effect of magnetic field parameter $M$ is to decrease the values of $f^{\prime \prime}(0)$, $-\left(1+4 R_{d} / 3\right) \theta^{\prime}(0)$, and $-\phi^{\prime}(0)$. The skin friction coefficient $f^{\prime \prime}(0)$ decreases with the increase of power-law index $n$. 
TABLE 2: Computations of the Nusselt number, skin friction coefficient, and the Sherwood number for various values of $n$ and $M$.

\begin{tabular}{lcccc}
\hline$n$ & $M$ & $f^{\prime \prime}(0)$ & $-\left(1+4 R_{d} / 3\right) \theta^{\prime}(0)$ & $-\phi^{\prime}(0)$ \\
\hline \multirow{2}{*}{0.6} & 0 & 3.67583 & 2.1486 & 2.5703 \\
& 2 & 3.43416 & 2.1039 & 2.5378 \\
\hline \multirow{3}{*}{1.0} & 5 & 3.30083 & 2.0674 & 2.5167 \\
& 0 & 2.48416 & 2.417 & 2.8058 \\
\hline \multirow{3}{*}{1.6} & 2 & 2.3783 & 2.3856 & 2.7928 \\
& 5 & 2.3458 & 2.3511 & 2.7822 \\
\hline
\end{tabular}

TABLE 3: Computations of the Nusselt number, skin friction coefficient, and the Sherwood number for various values of $n$ and $N t$.

\begin{tabular}{lllcr}
\hline$n$ & $N t$ & $f^{\prime \prime}(0)$ & $-\left(1+4 R_{d} / 3\right) \theta^{\prime}(0)$ & $-\phi^{\prime}(0)$ \\
\hline \multirow{3}{*}{0.6} & 0.1 & 3.4350 & 2.1045 & 2.5381 \\
& 0.4 & 3.4652 & 2.0815 & 2.4863 \\
\hline \multirow{3}{*}{1.0} & 0.7 & 3.4933 & 2.0591 & 2.4399 \\
\hline & 0.1 & 2.3783 & 2.3856 & 2.7928 \\
1.6 & 0.4 & 2.3957 & 2.3594 & 2.7357 \\
& 0.7 & 2.4142 & 2.3332 & 2.6843 \\
\hline
\end{tabular}

TABle 4: Computations of the Nusselt number, skin friction coefficient, and the Sherwood number for various values of $n$ and $N b$.

\begin{tabular}{lllcl}
\hline$n$ & $N b$ & $f^{\prime \prime}(0)$ & $-\left(1+4 R_{d} / 3\right) \theta^{\prime}(0)$ & $-\phi^{\prime}(0)$ \\
\hline \multirow{2}{*}{0.6} & 0.2 & 3.4308 & 2.0872 & 2.5483 \\
& 0.6 & 3.4300 & 2.0219 & 2.5551 \\
\hline \multirow{2}{*}{1.0} & 0.2 & 2.3758 & 2.3684 & 2.8038 \\
& 0.6 & 2.3758 & 2.3619 & 2.8114 \\
\hline \multirow{2}{*}{1.6} & 0.2 & 1.4333 & 2.5683 & 2.9810 \\
& 0.6 & 1.4333 & 2.4981 & 2.9846 \\
\hline
\end{tabular}

TABLE 5: Computations of the Nusselt number, skin friction coefficient, and the Sherwood number for various values of $\Lambda, a / c$, Le, $\operatorname{Pr}$, and $R_{d}$.

\begin{tabular}{|c|c|c|c|c|c|c|c|}
\hline$\Lambda$ & $a / c$ & Le & $\operatorname{Pr}$ & $R_{d}$ & $f^{\prime \prime}(0)$ & $-\left(1+4 R_{d} / 3\right) \theta^{\prime}(0)$ & $-\phi^{\prime}(0)$ \\
\hline-1 & 1.5 & 10 & 0.71 & 5 & 0.5400 & 2.1505 & 2.5521 \\
\hline 0 & 1.5 & 10 & 0.71 & 5 & 1.0258 & 2.2182 & 2.6209 \\
\hline 1 & 1.5 & 10 & 0.71 & 5 & 1.4925 & 2.2776 & 2.6832 \\
\hline 3 & 1.5 & 10 & 0.71 & 5 & 2.3873 & 2.3856 & 2.7928 \\
\hline 3 & 1.8 & 10 & 0.71 & 5 & 3.0008 & 2.5332 & 2.8682 \\
\hline 3 & 2.0 & 10 & 0.71 & 5 & 3.4425 & 2.6278 & 2.9193 \\
\hline 3 & 1.5 & 20 & 0.71 & 5 & 1.542 & 0.9756 & 1.6267 \\
\hline 3 & 1.5 & 30 & 0.71 & 5 & 1.0333 & 0.9756 & 1.9603 \\
\hline 3 & 1.5 & 10 & 1 & 5 & 2.3475 & 2.7862 & 2.7804 \\
\hline 3 & 1.5 & 10 & 10 & 5 & 2.0817 & 7.2348 & 2.5987 \\
\hline 3 & 1.5 & 10 & 100 & 5 & 1.8883 & 10.2348 & 2.5387 \\
\hline 3 & 1.5 & 10 & 0.71 & 10 & 2.4258 & 3.3600 & 2.8093 \\
\hline 3 & 1.5 & 10 & 0.71 & 15 & 2.4500 & 4.1597 & 2.8163 \\
\hline
\end{tabular}




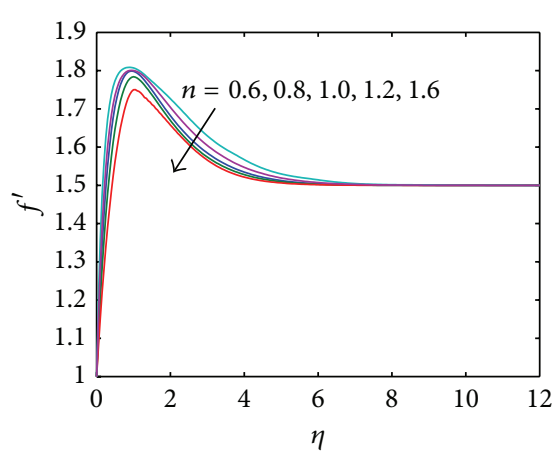

(a) Velocity

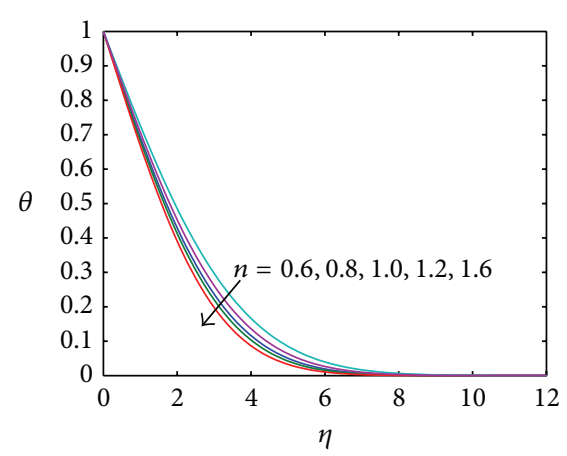

(b) Temperature

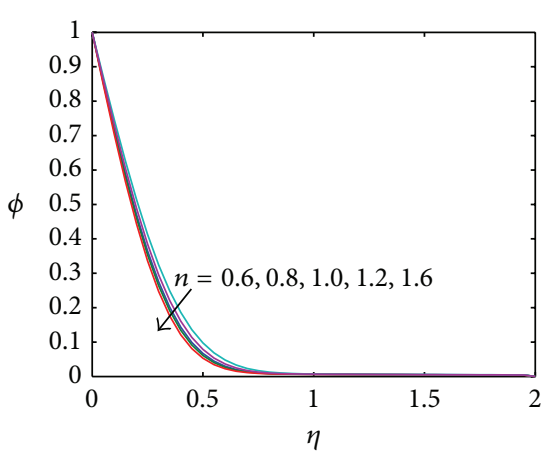

(c) Concentration

FIGURE 1: Effect of power-law index $n$ on velocity, temperature, and concentration profiles.

It is also observed that Nusselt number $-\left(1+4 R_{d} / 3\right) \theta^{\prime}(0)$ and Sherwood number $-\phi^{\prime}(0)$ increase with the increase of power-law index $n$. The skin friction coefficient $f^{\prime \prime}(0)$ value increases with the increase of thermophoresis parameter $N t$. Nusselt number $-\left(1+4 R_{d} / 3\right) \theta^{\prime}(0)$ and Sherwood number $-\phi^{\prime}(0)$ decrease with the increase of thermophoresis parameter $N t$. The effect of Brownian motion parameter $N b$ is to decrease with $f^{\prime \prime}(0)$ values in case of $n<1$ and it does not have any effect in case of $n=1$ and $n>1$. The effect of Brownian motion parameter $(\mathrm{Nb})$ is to decrease the Nusselt number $-\left(1+4 R_{d} / 3\right) \theta^{\prime}(0)$ and increase Sherwood number $-\phi^{\prime}(0)$ for Newtonian and non-Newtonian fluids.

From Table 5 it can be seen that skin friction coefficient $f^{\prime \prime}(0)$ is to increase with the increase of $\Lambda, a / c$, and $R_{d}$ whereas skin friction coefficient $f^{\prime \prime}(0)$ values decrease with the increase of Le, Pr. The Nusselt number $-\left(1+4 R_{d} / 3\right) \theta^{\prime}(0)$ and Sherwood number $-\phi^{\prime}(0)$ values increase with the increase of $\Lambda, a / c$, and $R_{d}$. As Le increases, Sherwood number $-\phi^{\prime}(0)$ increases. The effect of $\mathrm{Pr}$ is to increase Nusselt number $-\left(1+4 R_{d} / 3\right) \theta^{\prime}(0)$ and decrease the Sherwood number $-\phi^{\prime}(0)$.

Figures $1(a)-1(c)$ illustrate the variation of velocity, temperature, and nanoparticles volume fraction profiles, respectively, for different values of power-law index $n$. The velocity, temperature and nanoparticles volume fraction profiles decrease with the increase of power-law index $n$ from 0.6 to 1.6. The effect of the increased values of $n$ is to reduce the boundary layer thickness. It can be observed from Figure 1(b) that the effect of power-law index $n$ increases from 0.6 to 1.6 ; the temperature profiles decrease with an increasing viscosity of nanofluid, and thermal diffusion is depressed in the resume which cools the boundary layer and decreases the boundary layer thickness. It can also be seen from Figure 1(c) that the increase of power-law index $n$ from 0.6 to 1.6 decreases the nanoparticle volume fraction which decreases diffusion of nanoparticle volume fraction (concentration) boundary layer thickness.

Figures 2(a)-2(c) are drawn for the velocity, temperature, and concentration profiles for different values of Prandtl number Pr for the cases shear-thinning $(n<1)$, Newtonian $(n=1)$, and shear-thickening $(n>1)$ fluids. The effect of
Prandtl number Pr is to reduce the velocity and temperature profiles for both Newtonian and non-Newtonian fluids. Physically, fluids with smaller Prandtl number Pr have larger thermal diffusivity. Figure 2(c) indicated that increasing Prandtl number Pr leads to increase of the concentration profile for both Newtonian and non-Newtonian fluids.

The effect of thermophoresis parameter $\mathrm{Nt}$ is to increase velocity, temperature, and concentration profiles for both Newtonian and non-Newtonian fluids are noticed in Figure 3.

Figure 4 exhibits dimensionless temperature and concentration profiles for various values of Brownian motion parameter $\mathrm{Nb}$. It can be seen that the temperature profile slightly increases with an increase in the value of Brownian motion parameter $\mathrm{Nb}$. The concentration profiles decrease with the value of Brownian motion parameter $\mathrm{Nb}$ which is noticed from these Figures 4(a) and 4(b).

Figure 5 shows the effect of thermal buoyancy ratio $N$ on velocity profiles for shear-thinning $(n<1)$, Newtonian $(n=1)$, and shear-thickening $(n>1)$ fluids, respectively. It is noticed that the increase of $N$ values has a tendency to increase the buoyancy effects changing more induced flow along the stretching sheet in the vertical direction reflected by the increase in the fluid velocity. This enhancement in the fluid velocity has more in shear-thinning fluid $(n<1)$ than shear-thickening fluid $(n>1)$.

Figure 6(a) shows the effect of radiation parameter $R_{d}$ on the velocity profiles for both Newtonian and non-Newtonian fluids. It is noticed from the figure that the velocity of the fluid increases with the increase of radiation parameter $R_{d}$ values. It can be shown from Figure 6(b) that temperature of the fluid increases with the increase of radiation parameter $R_{d}$. As expected, an increase of the radiation parameter $R_{d}$ has the tendency to increase the effect of conduction as well as increasing the temperature at each point away from the surface. Hence, higher values of radiation parameter $R_{d}$ imply a higher surface heat flux.

The variations in heat source/sink parameter $Q$ on velocity and temperature profiles are given in Figure 7; from the figure it can be seen that the velocity as well as temperature profiles increases with the increase of heat source/sink parameter $Q$. A gradually increasing heat source/sink parameter 

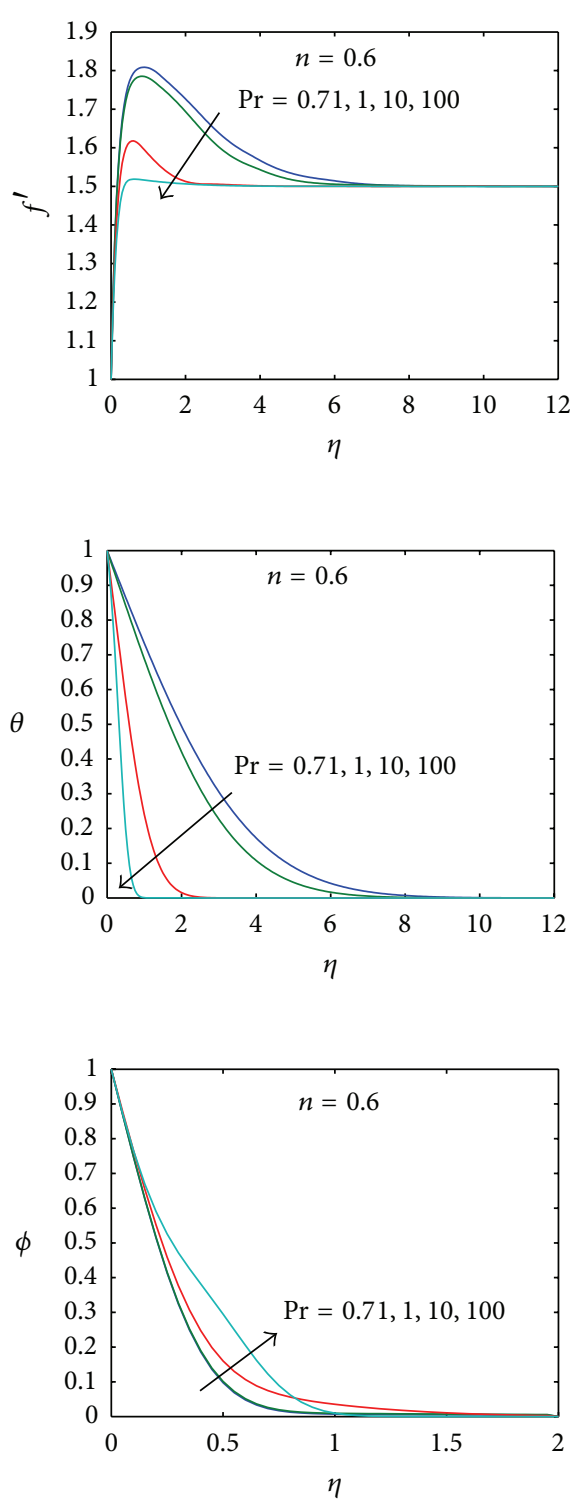

(c) Concentration
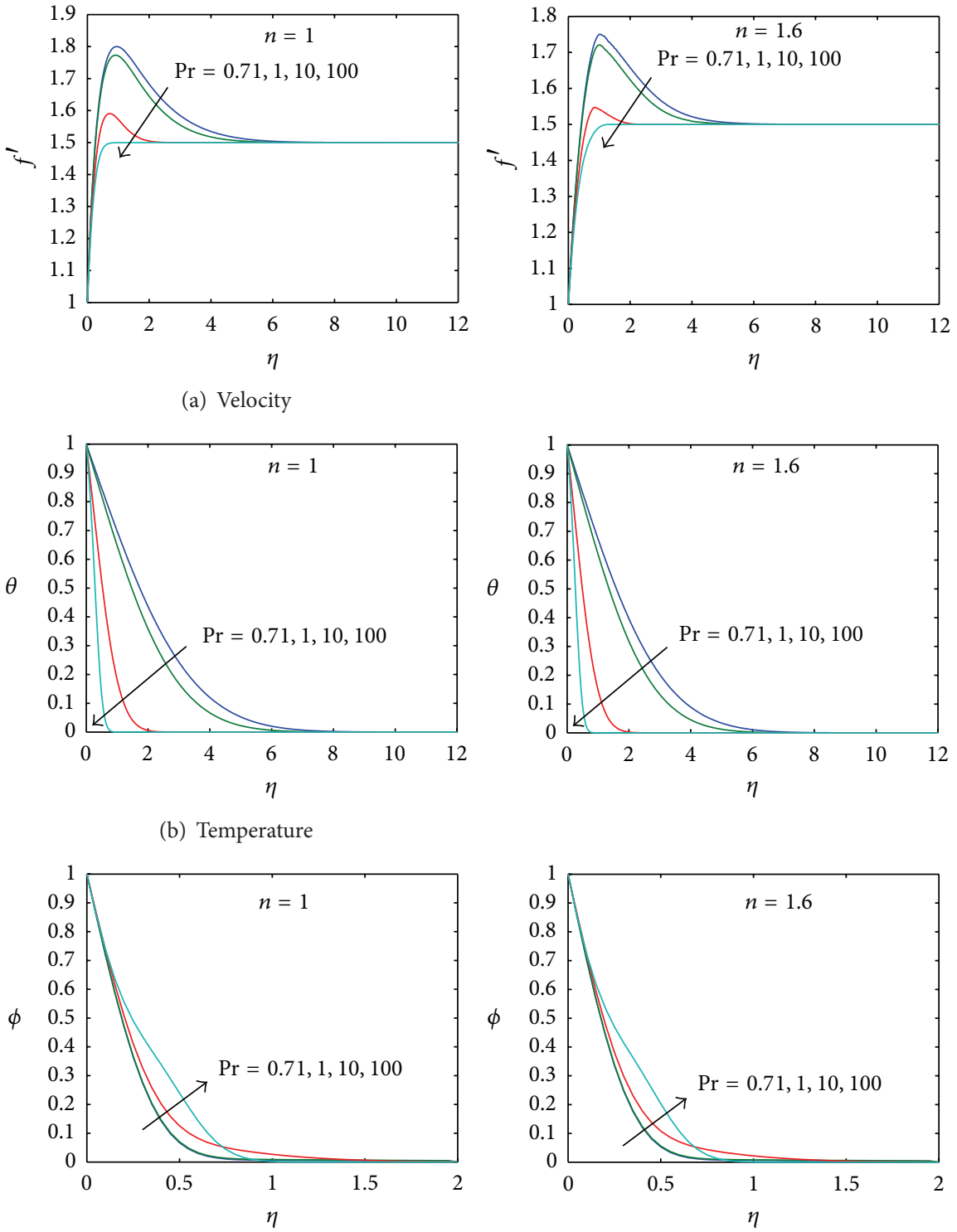

(a) Velocity
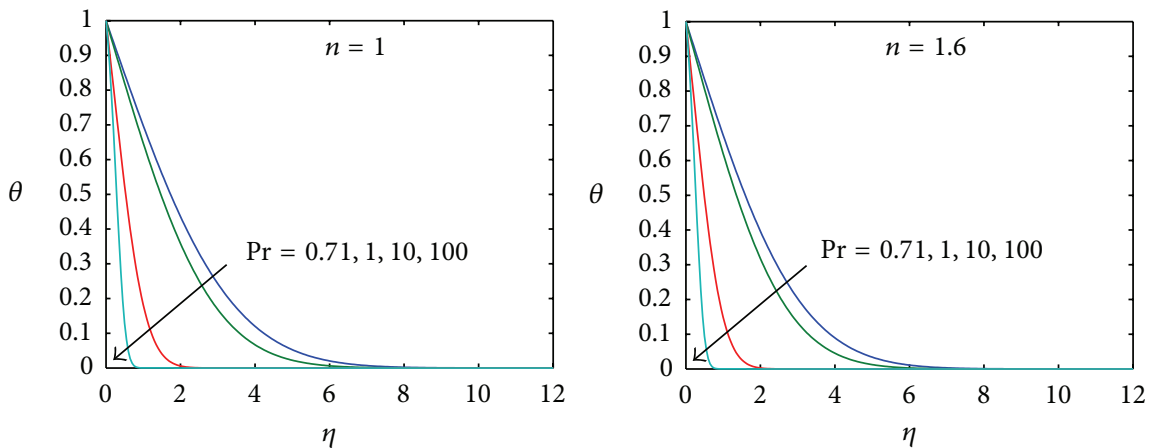

(b) Temperature

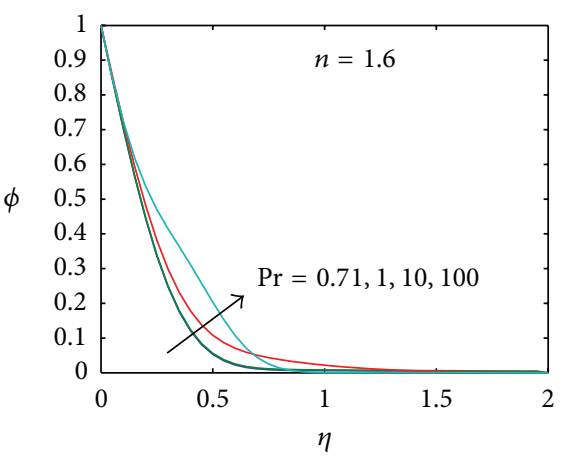

FIGURE 2: Effect of Pr on velocity, temperature, and concentration profiles for pseudoplastic, Newtonian, and dilatant fluids.

increases the thermal boundary layer thickness which physically reveals the fact that an increase in the heat source/sink parameter means an increase in the heat generated inside the boundary layer which leads to higher temperature field. It is noted that the temperature profiles decrease for increasing strength of heat sink and due to increase of heat source strength the temperature increases. So the thickness of the thermal boundary layer reduces for increase with heat source parameter. These results are very much significant for the flow where heat transfer is given prime importance.

Figures $8(\mathrm{a})-8(\mathrm{c})$ present the changes in the velocity profiles with the effect of magnetic parameter $M$ for shearthinning $(n<1)$, Newtonian $(n=1)$, and shear-thickening $(n>1)$ fluids, respectively. The velocity profiles $f^{\prime}$ decrease with the raising of magnetic parameter $M$. This is due to magnetic field opposing the transport phenomena, since the variation of magnetic parameter $M$ causes the variation of Lorentz forces. The Lorentz force is a drag like force that produces more resistance to transport phenomena and that causes reduction in the fluid velocity. The effect of magnetic field is more in shear-thinning fluids than shearthickening fluids. The effect of magnetic fields is very meager on temperature profiles; hence, it is not shown.

Figures 9(a)-9(c) show the effect of dimensionless mixed convection parameter $\Lambda$ on velocity, temperature, and concentration profiles, respectively. The velocity profiles are increasing with increasing values of $\Lambda$ whereas temperature and concentration profiles are decreasing with increasing values of $\Lambda$. The presence of the thermal buoyancy effects represented by finite values of the mixed parameter has 

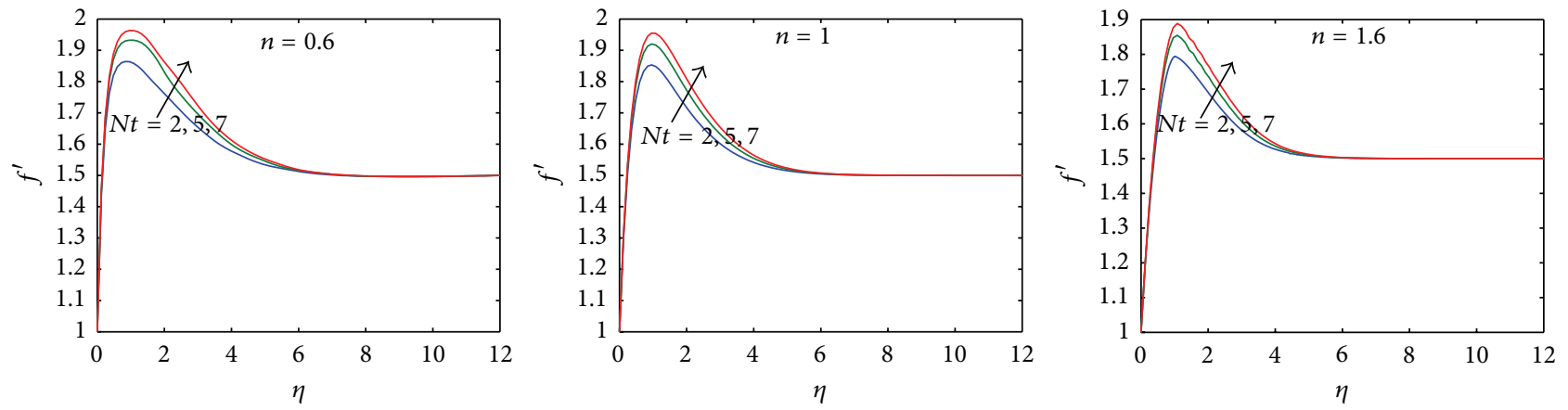

(a) Velocity
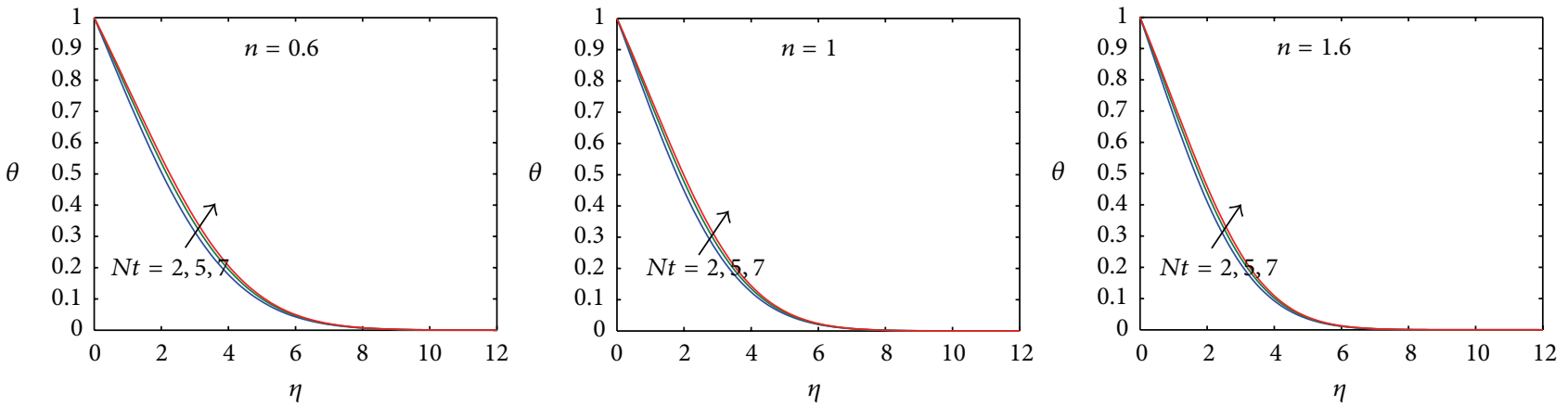

(b) Temperature
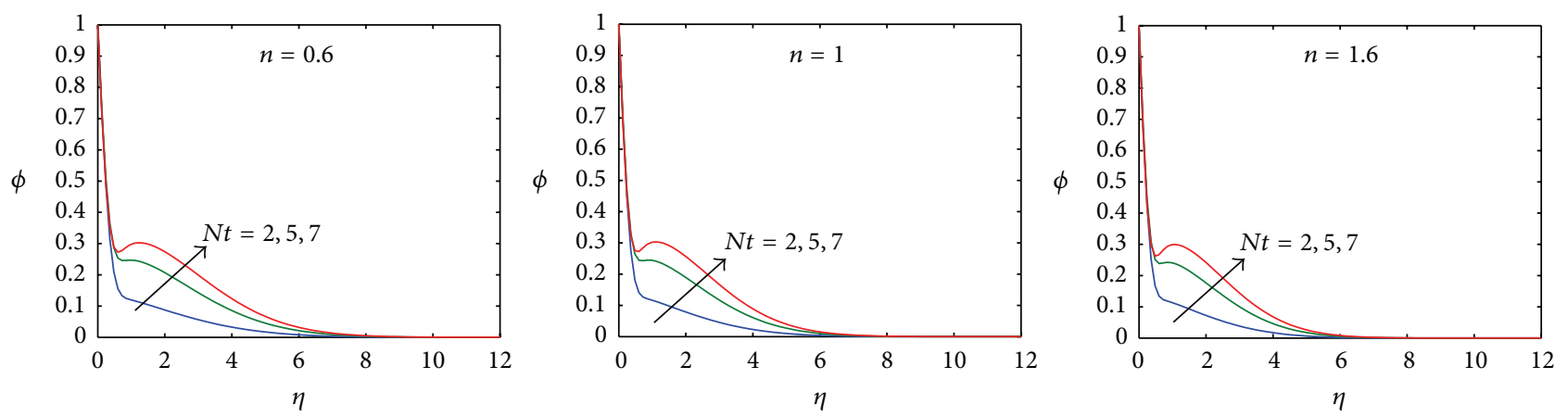

(c) Concentration

FIGURE 3: Effect of $N t$ on velocity, temperature, and concentration profiles for pseudoplastic, Newtonian, and dilatant fluids.

the tendency to induce more flow along the surface at the expense of small reductions in the temperature and concentration. Distinctive peaks in the velocity profiles which are characteristics of free convection flows are also observed as $\Lambda$ increases.

Figure 10 depicts the variation of nanoparticle concentration profiles for Newtonian and non-Newtonian fluids with different values of Lewis number Le. The concentration profile is decreased due to the increase of Lewis number Le. Increase in the Lewis number Le reduces the nanoparticle volume fraction and its boundary layer thickness.

Figures 11(a)-11(c) present the velocity, temperature, and concentration profiles for various values of ratio of velocity parameter $a / c$. It can be observed that an increase in $a / c$ causes increase in velocity profiles and significant decrease on the temperature and concentration profiles. These behaviours are clearly shown in Figure 11.

\section{Conclusions}

The influence of Brownian motion and thermophoresis on mixed convection magneto hydrodynamic boundary layer flow of heat and mass transfer stagnation-point flow of power-law non-Newtonian nanofluid towards a stretching surface is investigated. Various thermal radiation and heat source/sink parameters have been considered for the flow, temperature, and nanoparticle volume fraction as well as the skin friction coefficient, Nusselt number, and Sherwood 

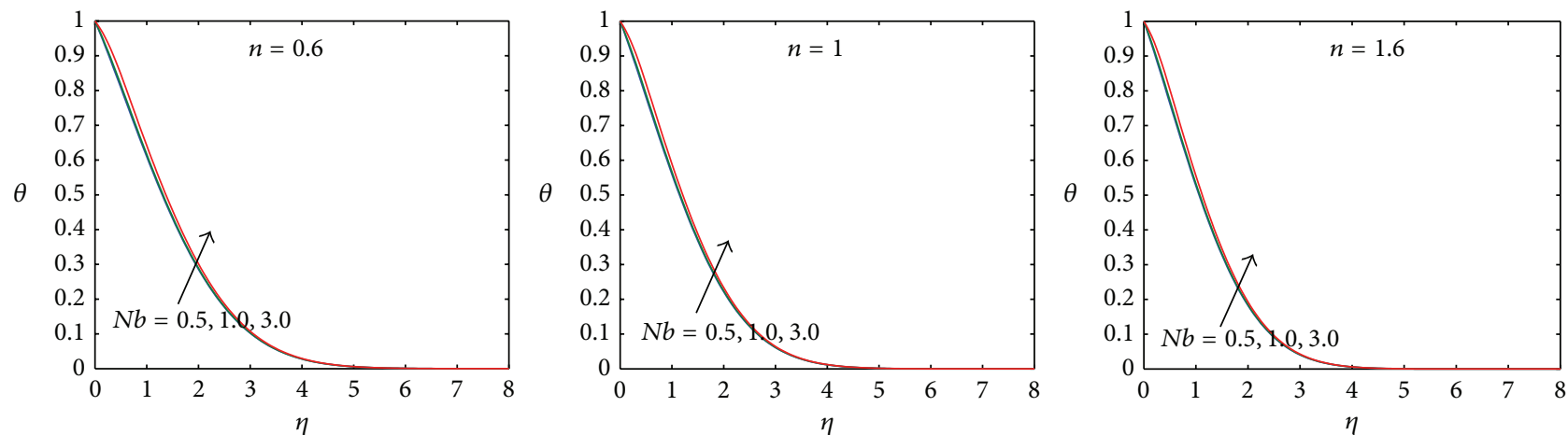

(a) Temperature
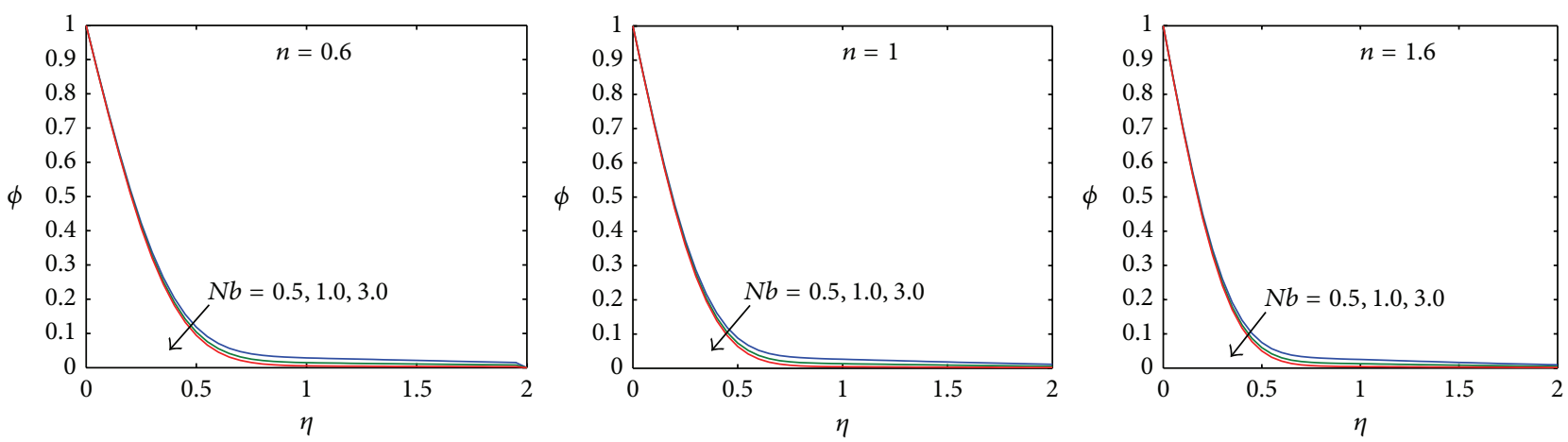

(b) Concentration

Figure 4: Effect of $\mathrm{Nb}$ on temperature and concentration profiles for pseudoplastic, Newtonian, and dilatant fluids.

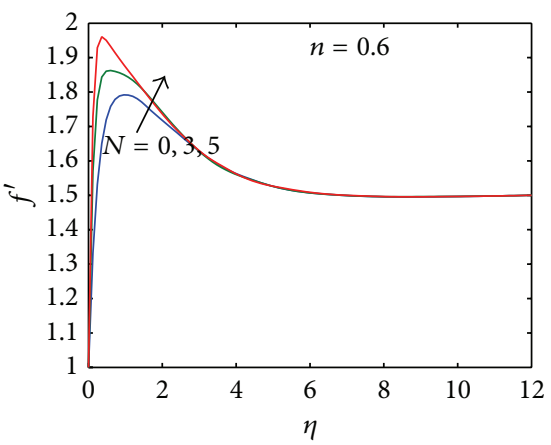

(a)

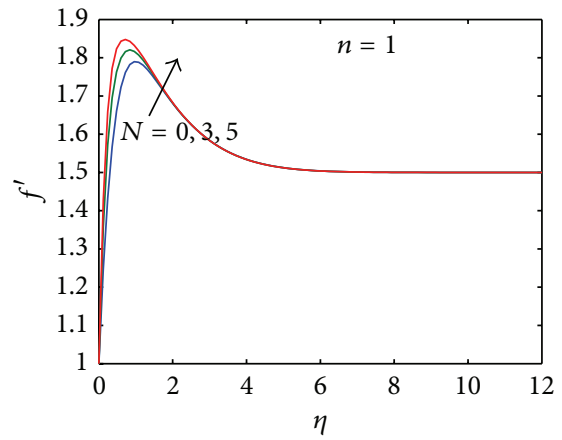

(b)

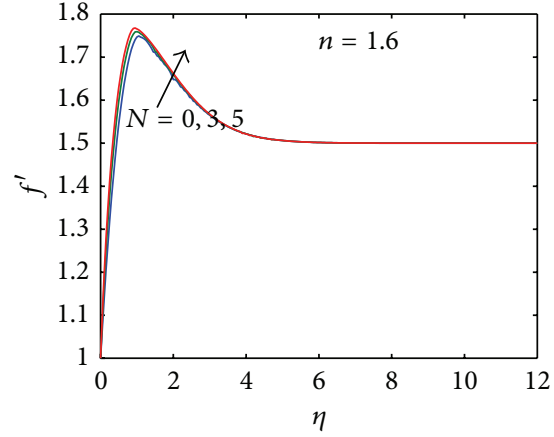

(c)

FIGURE 5: Effect of $N$ on velocity profiles for pseudoplastic, Newtonian, and dilatant fluids.

number. The main findings of the present study can be summarised as follows.

(i) The effect of Magnetic field parameter $M$ reduces the velocity profiles.

(ii) The influence of thermophoresis $N t$ increases the velocity, temperature, and concentration profiles for the cases of pseudoplastic, Newtonian, and dilatant fluids. The effect of Brownian motion $\mathrm{Nb}$ is to increase the temperature profiles and decrease the concentration profiles.

(iii) The velocity and concentration profiles increase with the increase of radiation parameter $R_{d}$ and heat source/sink parameter $Q$ for both Newtonian and non-Newtonian fluids.

(iv) The effect of mixed convection parameter $\Lambda$ and velocity ratio parameter $a / c$ is to increase the velocity 

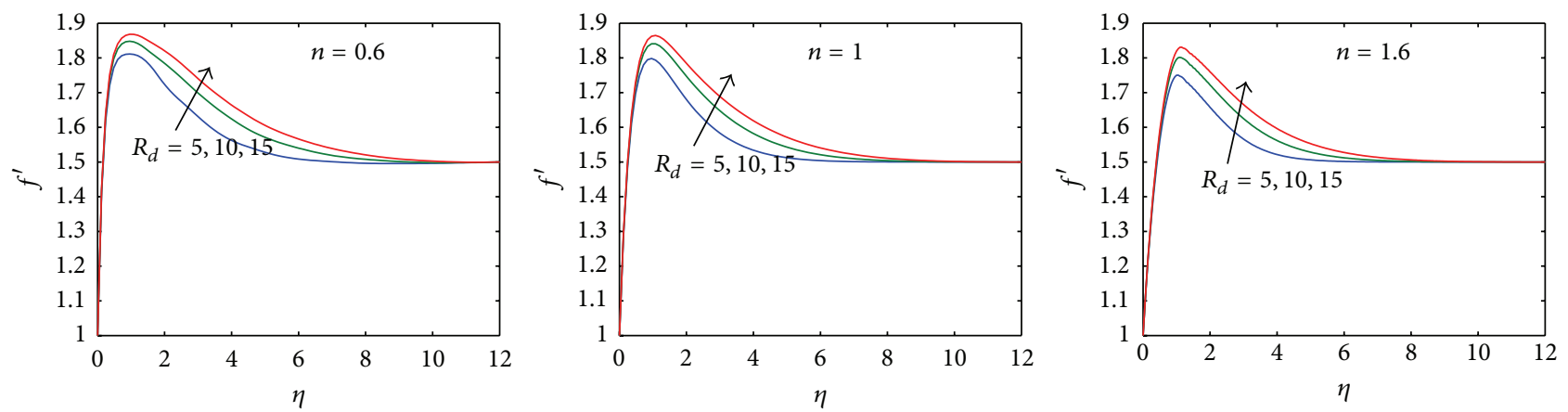

(a) Velocity
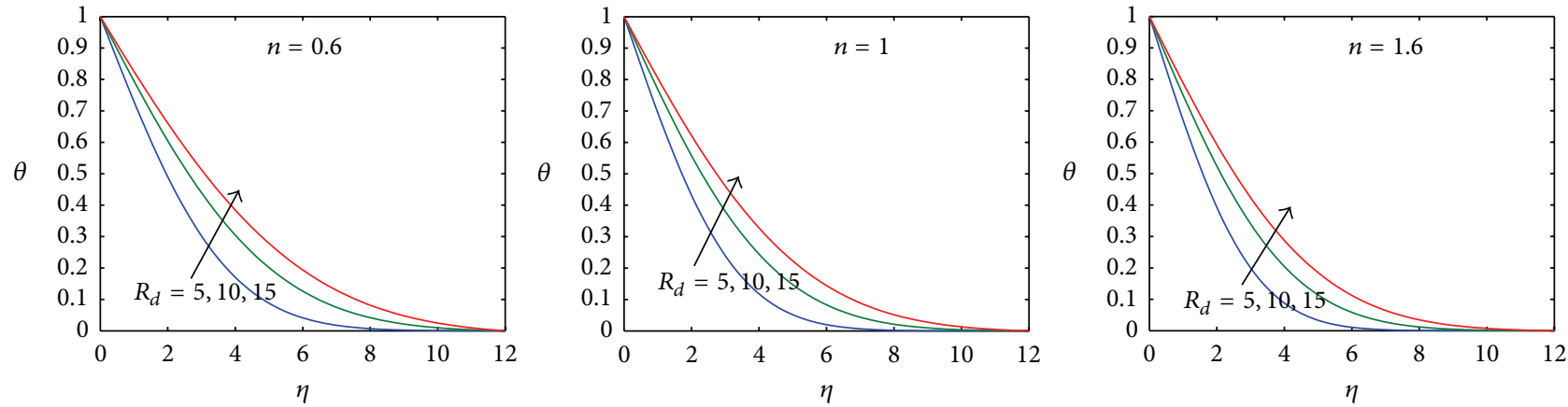

(b) Temperature

Figure 6: Effect of $R_{d}$ on velocity and temperature profiles for pseudoplastic, Newtonian, and dilatant fluids.
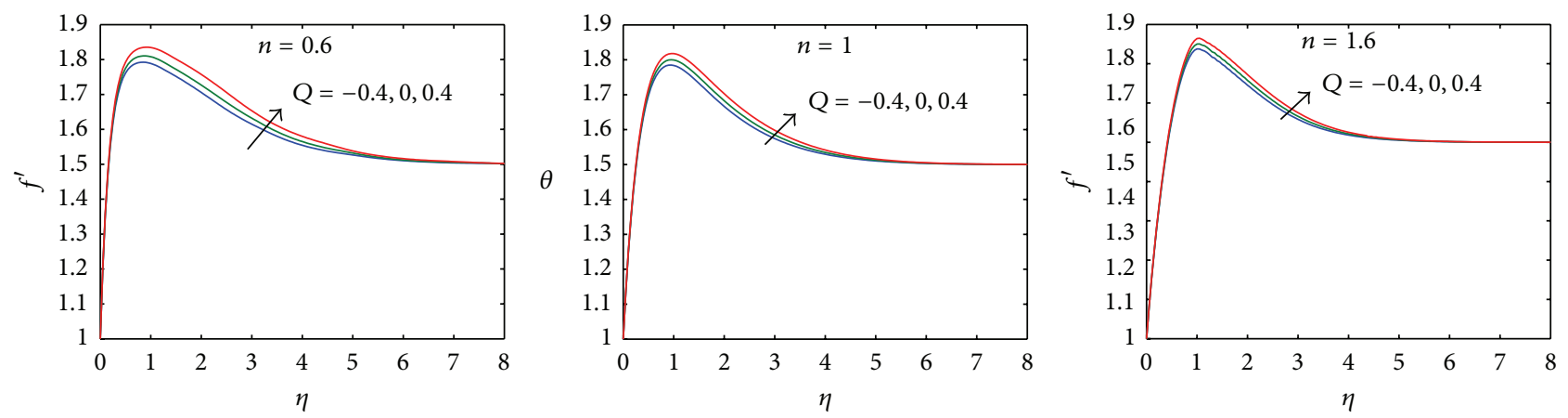

(a) Velocity
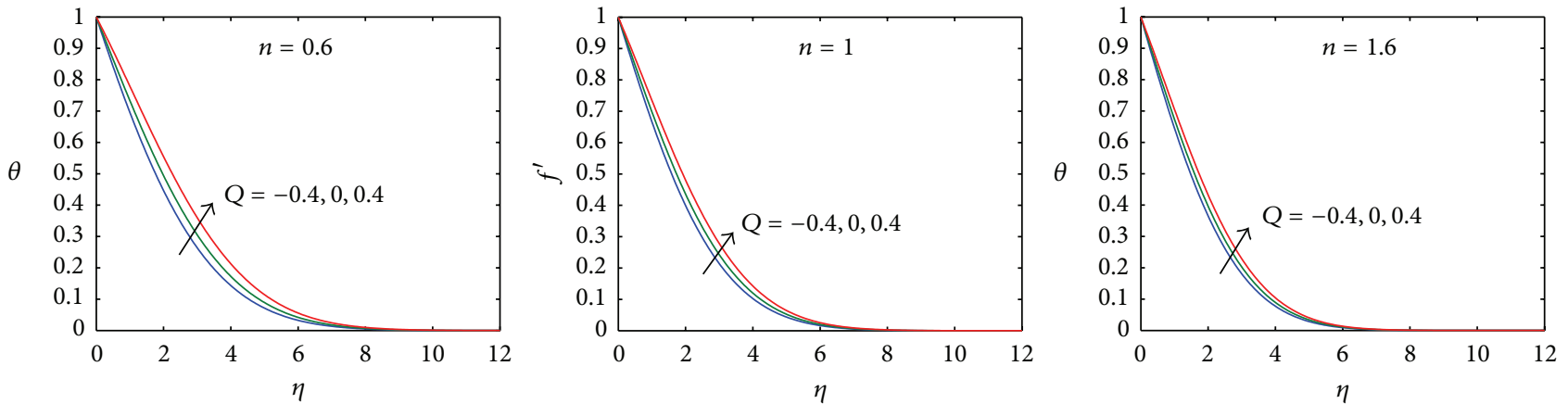

(b) Temperature

FIGURE 7: Effect of $Q$ on velocity and temperature profiles for pseudoplastic, Newtonian, and dilatant fluids. 


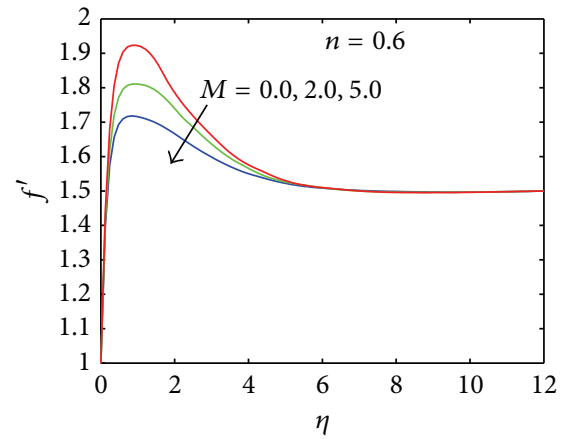

(a)

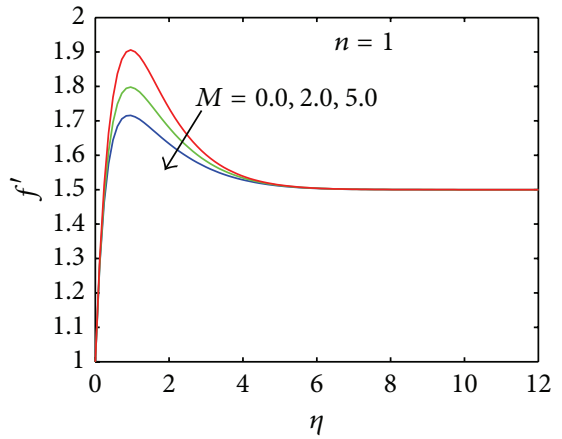

(b)

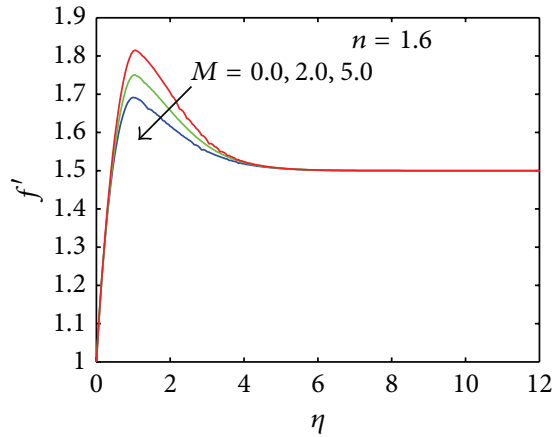

(c)

FIGURE 8: Effect of $M$ on velocity profiles for pseudoplastic, Newtonian and dilatant fluids.

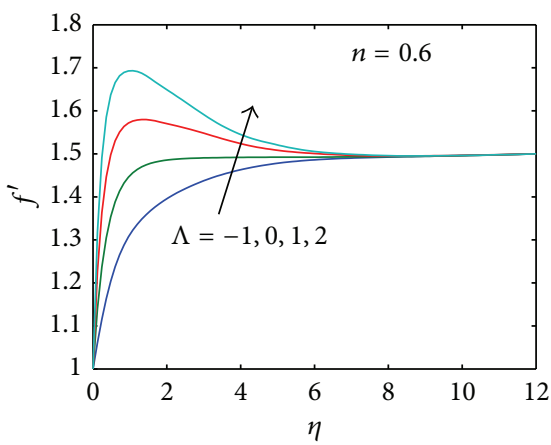

(a) Velocity

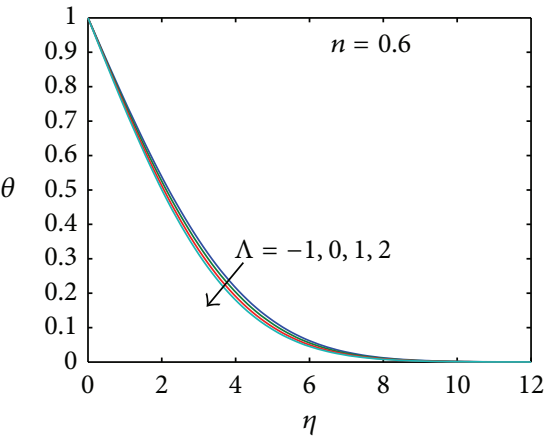

(b) Temperature

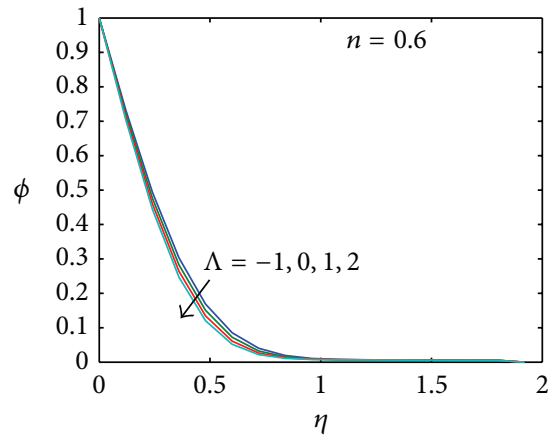

(c) Concerntration

FIGURE 9: Effect of $\Lambda$ on the velocity, temperature, and concentration profiles for $n=0.6$.

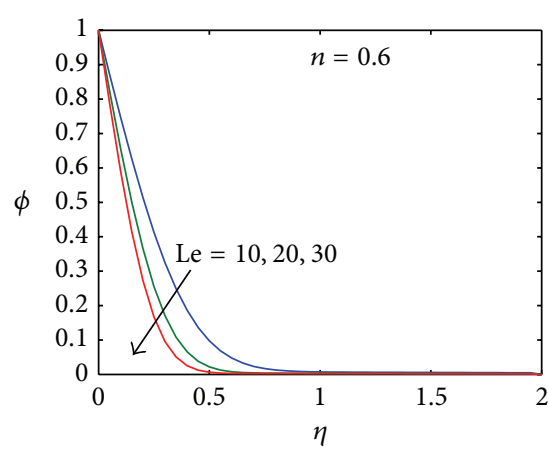

(a)

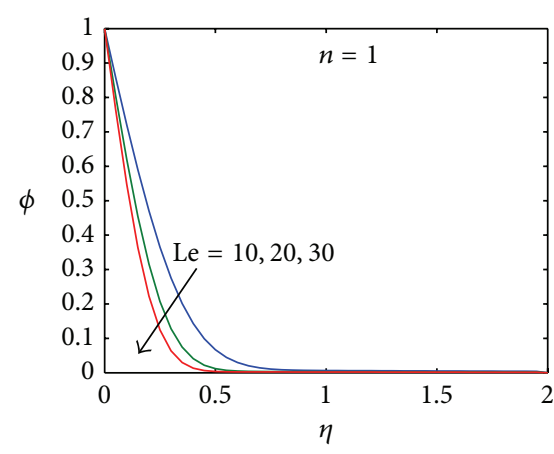

(b)

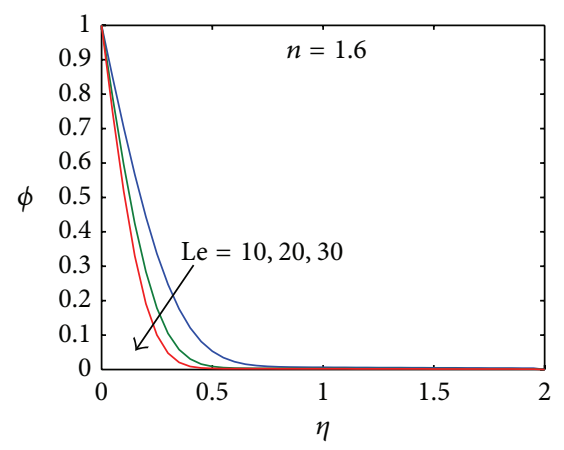

(c)

Figure 10: Effect of Le on concentration profiles for pseudoplastic, Newtonian, and dilatant fluids.

profiles and reduces the temperature and concentration profiles.

(v) The skin friction coefficient $f^{\prime \prime}(0)$ increases with the increase of thermophoresis parameter $N t$ and it decreases with the increase of Brownian motion parameter $\mathrm{Nb}$ and the power-law index $n$. The coefficient of Nusselt number and Sherwood number decreases with the increase of $N t$.

\section{Conflict of Interests}

The authors declare that there is no conflict of interests regarding the publication of this paper. 


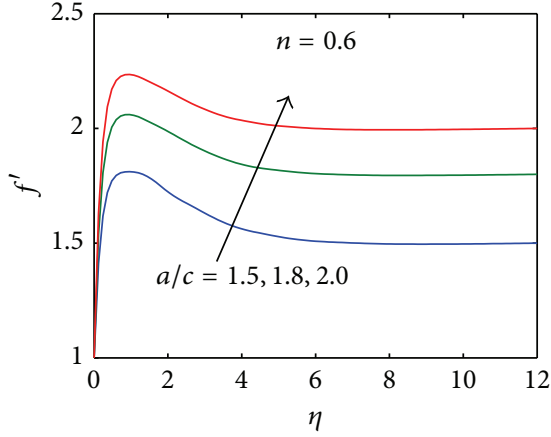

(a) Velocity

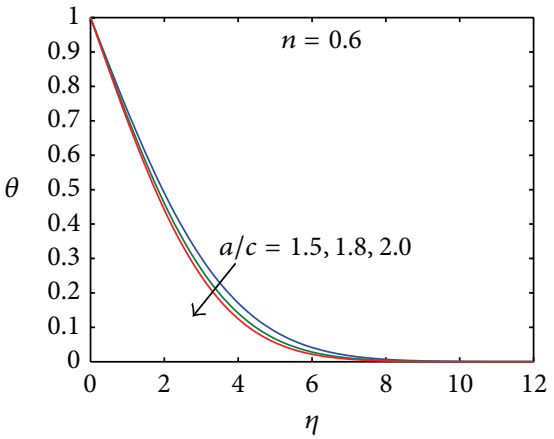

(b) Temperature

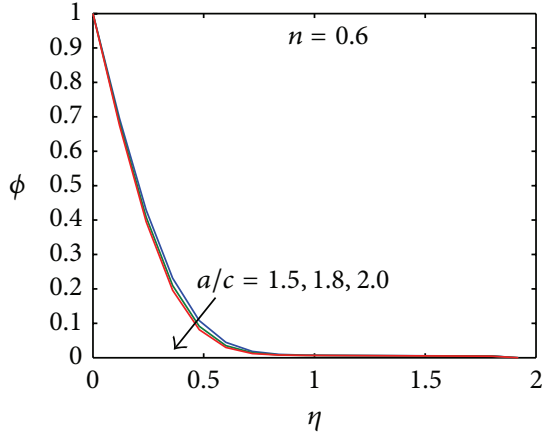

(c) Concentration

FIGURE 11: Effect of $a / c$ on the velocity, temperature, and concentration profiles for $n=0.6$.

\section{References}

[1] W. R. Schowalter, "The application of boundary-layer theory to power-law pseudoplastic fluids: similar solutions," AIChE Journal, vol. 6, no. 1, pp. 24-28, 2004.

[2] A. Acrivos, "On laminar boundary layer flows with a rapid homogeneous chemical reaction," Chemical Engineering Science, vol. 13, no. 2, pp. 57-62, 1960.

[3] E. M. A. Elbashbeshy, T. G. Emam, and M. S. Abdel-Wahed, "Three-dimensional flow over a stretching surface with thermal radiation and heat generation in the presence of chemical reaction and suction/injection," International Journal of Energy Technology, vol. 16, pp. 1-8, 2011.

[4] S. Nadeem, T. Hayat, M. Y. Malik, and S. A. Rajput, “Thermal radiation effects on the flow by an exponentially stretching surface: a series solution," Zeitschrift fur NaturforschungSection, vol. 65, no. 6-7, pp. 495-503, 2010.

[5] S. Nadeem, A. Hussain, and K. Vajravelu, "Effects of heat transfer on the stagnation flow of a third order fluid over a shrinking sheet," Zeitschrift für Naturforschung, vol. 65, no. 11, pp. 969-994, 2010.

[6] S. Nadeem, A. Hussain, and M. Khan, "HAM solutions for boundary layer flow in the region of the stagnation point towards a stretching sheet," Communications in Nonlinear Science and Numerical Simulation, vol. 15, no. 3, pp. 475-481, 2010.

[7] S. Nadeem and N. S. Akbar, "Influence of heat transfer on a peristaltic flow of Johnson Segalman fluid in a non uniform tube," International Communications in Heat and Mass Transfer, vol. 36, no. 10, pp. 1050-1059, 2009.

[8] S. Nadeem and M. Ali, "Analytical solutions for pipe flow of a fourth grade fluid with Reynold and Vogel's models of viscosities," Communications in Nonlinear Science and Numerical Simulation, vol. 14, no. 5, pp. 2073-2090, 2009.

[9] J. Buongiorno, "Convective transport in nanofluids," Journal of Heat Transfer, vol. 128, no. 3, pp. 240-250, 2006.

[10] G. Łukaszewicz, "Asymptotic behavior of micropolar fluid flows," International Journal of Engineering Science, vol. 41, no. 3-5, pp. 259-269, 2003.

[11] A. V. Shenoy, "Non-Newtonian fluid heat transfer in porous media," Advances in Heat Transfer, vol. 24, pp. 101-190, 1994.

[12] G. Astarita and G. Marrucci, Principles of Non-Newtonian Fluid Mechanics, McGraw-Hill, New York, NY, USA, 1974.

[13] H. Bohme, Non-Newtonian Fluid Mechanics, North-Holland Series in Applied Mathematics and Mechanics, North-Holland, 1987.
[14] N. Kishan and B. Shashidar Reddy, "MHD Effects on NonNewtonian power-law fluid past a continuously moving porous flat plate with heat flux and viscous dissippation," International Journal of Applied Mechanics and Engineering, vol. 18, no. 2, pp. 425-445, 2013.

[15] S. Nadeem, A. Riaz, R. Ellahi, and N. S. Akbar, "Effects of heat and mass transfer on peristaltic flow of a nanofluid between eccentric cylinders," Applied Nanoscience, vol. 4, pp. 393-404, 2014.

[16] D. W. Zhou, "Heat transfer enhancement of copper nanofluid with acoustic cavitation," International Journal of Heat and Mass Transfer, vol. 47, no. 14-16, pp. 3109-3117, 2004.

[17] S. U. S. Choi, "Enhancing thermal conductivity of fluids with nanoparticles," ASME Fluids Engineering Division, vol. 231, pp. 99-105, 1995.

[18] Y. Xuan and Q. Li, "Investigation on convective heat transfer and flow features of nanofluids," Journal of Heat Transfer, vol. 125, no. 1, pp. 151-155, 2003.

[19] B. C. Pak and Y. I. Cho, "Hydrodynamic and heat transfer study of dispersed fluids with submicron metallic oxide particles," Experimental Heat Transfer, vol. 11, no. 2, pp. 151-170, 1998.

[20] D. S. Wen and Y. L. Ding, "Effective thermal conductivity of aqueous suspensions of carbon nanotubes (Nanouids)," Journal of Thermophysics and Heat Transfer, vol. 18, no. 4, pp. 481-485, 2004.

[21] Y. L. Ding, H. Alias, D. S. Wen, and R. A. Williams, "Heat transfer of aqueous suspensions of carbon nanotubes (CNT nanofluids)," International Journal of Heat and Mass Transfer, vol. 49, no. 1-2, pp. 240-250, 2006.

[22] H. Masuda, A. Ebata, K. Teramae, and N. Hishinuma, "Alteration of thermal conductivity and viscosity of liquid by dispersing ultra-fine particles (dispersion of $\mathrm{G}-\mathrm{Al}_{2} \mathrm{O}_{3}, \mathrm{SiO}_{2}$ and $\mathrm{TiO}_{2}$ ultra-fine particles)," Netsu Bussei, vol. 7, no. 4, pp. 227-233, 1993.

[23] P. Keblinski, S. R. Phillpot, S. U. S. Choi, and J. A. Eastman, "Mechanisms of heat flow in suspensions of nano-sized particles (nanofluids)," International Journal of Heat and Mass Transfer, vol. 45, no. 4, pp. 855-863, 2001.

[24] D. T. Wasan and A. D. Nikolov, "Spreading of nanofluids on solids," Nature, vol. 423, no. 6936, pp. 156-159, 2003.

[25] A. Chengara, A. D. Nikolov, D. T. Wasan, A. Trokhymchuk, and D. Henderson, "Spreading of nanofluids driven by the structural disjoining pressure gradient," Journal of Colloid and Interface Science, vol. 280, no. 1, pp. 192-201, 2004. 
[26] S. M. You, J. H. Kim, and K. H. Kim, "Effect of nanoparticles on critical heat flux of water in pool boiling heat transfer," Applied Physics Letters, vol. 83, no. 16, pp. 3374-3376, 2003.

[27] L. J. Crane, "Flow past a stretching plate," Zeitschrift für Angewandte Mathematik und Physik ZAMP, vol. 21, no. 4, pp. 645-647, 1970.

[28] P. Carragher and L. J. Crane, "Heat transfer on a continuous stretching sheet," Zeitschrift für Angewandte Mathematik und Mechanik, vol. 62, pp. 564-573, 1982.

[29] R. Ellahi, M. Raza, and K. Vafai, "Series solutions of nonNewtonian nanofluids with Reynolds' model and Vogel's model by means of the Homotopy analysis method," Mathematical and Computer Modelling, vol. 55, no. 7-8, pp. 1876-1891, 2012.

[30] R. Cortell, "Flow and heat transfer of a fluid through a porous medium over a stretching surface with internal heat generation/ absorption and suction/blowing," Fluid Dynamics Research, vol. 37, no. 4, pp. 231-245, 2005.

[31] M. S. Abel, M. M. Nandeppanavar, and M. B. Malkhed, "Hydromagnetic boundary layer flow and heat transfer in viscoelastic fluid over a continuously moving permeable stretching surface with nonuniform heat source/sink embedded in fluid-saturated porous medium," Chemical Engineering Communications, vol. 197, no. 5, pp. 633-655, 2010.

[32] H. Dessie and N. Kishan, "MHD effects on heat transfer over stretching sheet embedded in porous medium with variable viscosity, viscous dissipation and heat source/sink," Ain Shams Engineering Journal, vol. 5, no. 3, pp. 967-977, 2014.

[33] M. N. Tufail, A. S. Butt, and A. Ali, "Heat source/sink effects on non-Newtonian MHD fluid flow and heat transfer over a permeable stretching surface: lie group analysis," Indian Journal of Physics, vol. 88, no. 1, pp. 75-82, 2014.

[34] E. M. A. Elbashbeshy and M. A. A. Bazid, "Heat transfer in a porous medium over a stretching surface with internal heat generation and suction or injection," Applied Mathematics and Computation, vol. 158, no. 3, pp. 799-807, 2004.

[35] C.-H. Chen, "Magneto-hydrodynamic mixed convection of a power-law fluid past a stretching surface in the presence of thermal radiation and internal heat generation/absorption," International Journal of Non-Linear Mechanics, vol. 44, no. 6, pp. 596-603, 2009.

[36] K. V. Prasad, K. Vajravelu, and P. S. Datti, "Mixed convection heat transfer over a non-linear stretching surface with variable fluid properties," International Journal of Non-Linear Mechanics, vol. 45, no. 3, pp. 320-330, 2010.

[37] A. B. Metzner, "Heat transfer in non-Newtonian fluid," Advances in Heat Transfer, vol. 2, pp. 357-397, 1965.

[38] T. R. Mahapatra, S. K. Nandy, and A. S. Gupta, "Analytical solution of magnetohydrodynamic stagnation-point flow of a power-law fluid towards a stretching surface," Applied Mathematics and Computation, vol. 215, no. 5, pp. 1696-1710, 2009. 

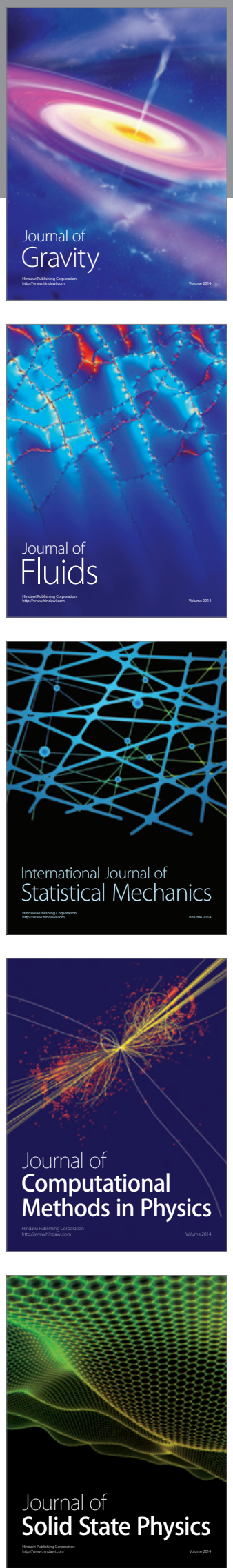

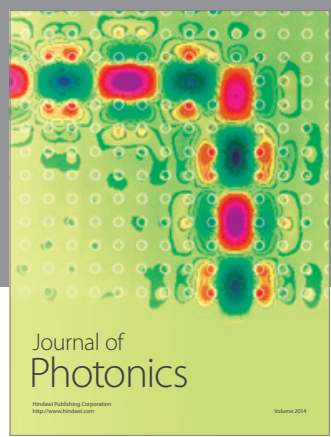

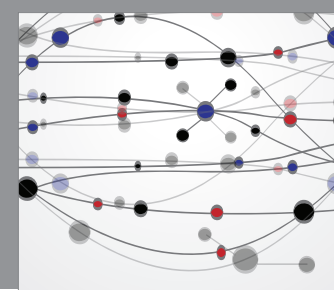

The Scientific World Journal

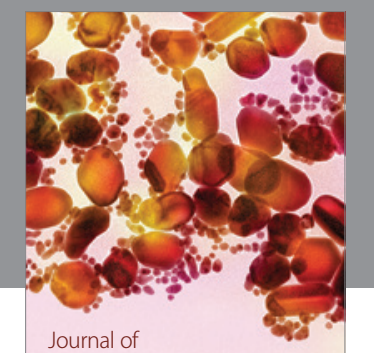

Soft Matter
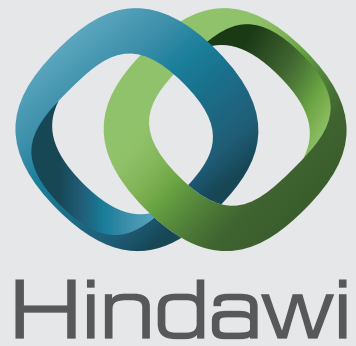

Submit your manuscripts at

http://www.hindawi.com
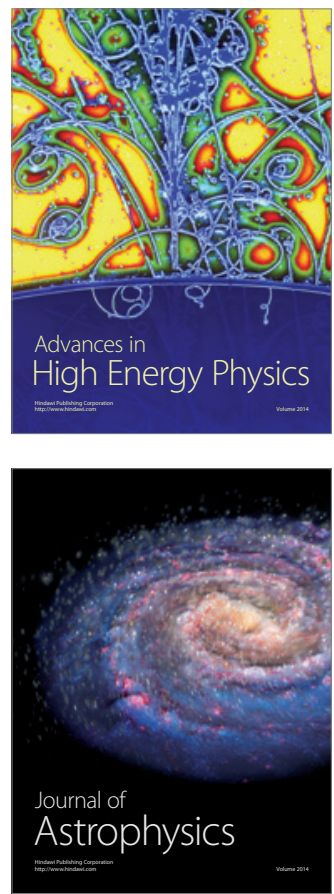
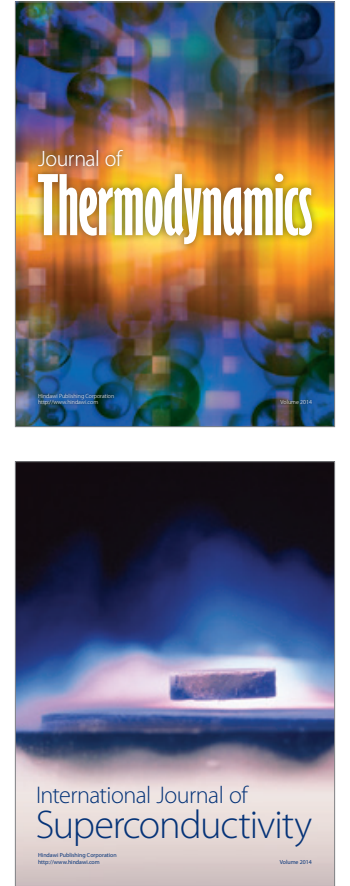
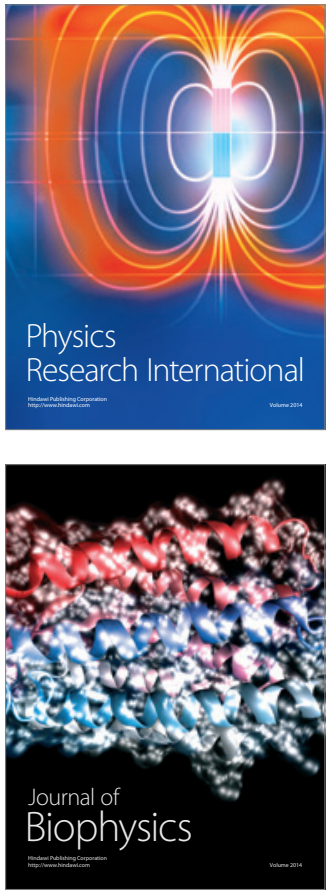
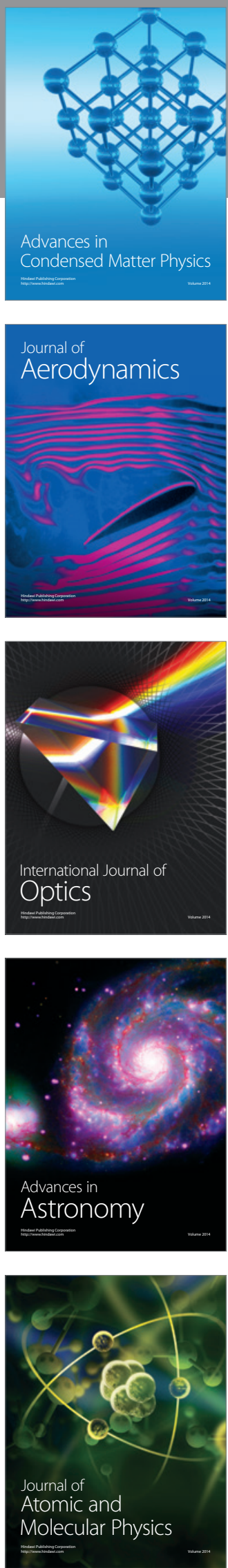